\title{
CORRUPÇÃO NA PETROBRAS PRECISA SER APURADA COM RIGOR PELO TCU E CGU
}

Coluna publicada em 13.1.2015: <http://www.conjur.com.br/2015-jan-13/ contas-vista-corrupcao-petrobras-apurada-rigor-tcu-cgu>

O mais recente escândalo que surgiu ano passado, e seguramente ocupará o noticiário neste ano de 2015, envolve atos de corrupção ligados à principal empresa estatal do país, a Petrobras.

A corrupção tem, lamentavelmente, tomado boa parte do noticiário nos últimos anos no Brasil, especialmente em razão do caso do mensalão, que agora tem tudo para ser sucedido pelos problemas envolvendo a Petrobras.

Oportuno tratar do tema sob a ótica do Direito Financeiro, que, ao ter como objeto de estudo a atividade financeira do setor público, não pode deixar de lado as empresas estatais, como a Petrobras e outras, ainda que dotadas de personalidade jurídica de direito privado.

Um dos aspectos mais interessantes nessa abordagem refere-se justamente à questão da fiscalização contábil, financeira e orçamentária, cujo sistema no Brasil é previsto nos artigos 70 e seguintes da Constituição, realizando-se por meio do controle interno e do controle externo, em cada esfera de governo, ${ }^{1}$ e seus órgãos têm grande responsabilidade na apuração e punição de desvios de recursos públicos.

O controle interno, cuja importância cresce a cada dia e tem importante papel no combate à corrupção, conforme já destacado em coluna anterior, é exercido, na esfera federal, pela Secretaria Federal de Controle Interno, órgão integrante da Controladoria Geral da União (CGU).

1 Art. 70. A fiscalização contábil, financeira, orçamentária, operacional e patrimonial da Uniāo e das entidades da administração direta e indireta, quanto à legalidade, legitimidade, economicidade, aplicação das subvenções e renúncia de receitas, será exercida pelo Congresso Nacional, mediante controle externo, e pelo sistema de controle interno de cada Poder. 
Dirigida pelo ministro Jorge Hage até o final do ano passado, a CGU experimentou nos últimos anos grande progresso em suas funções, mas, segundo noticiado, ${ }^{2}$ tem sido recentemente prejudicada em termos orçamentários, com diminuição de seus recursos, contingenciamento de dotaçóes e outras medidas que prejudicaram o seu pleno funcionamento e continuidade do avanço, o que não é um bom sinal.

A CGU já tem tomado medidas em relação à própria Petrobras, ${ }^{3}$ mas, conforme destacado pelo agora ex-ministro, os avanços do controle interno ainda necessitam ser aprimorados no que se refere justamente às empresas estatais, tendo havido nos primeiros anos de funcionamento da CGU um avanço na fiscalização da administração direta, sendo a fiscalização das estatais o próximo passo a ser seguido, não havendo ainda nelas instrumentos e suficiente transparência para uma adequada fiscalização. ${ }^{4}$

No âmbito do controle externo, releva destacar, no caso da Petrobras, empresa estatal constituída no âmbito federal, a atuação do Tribunal de Contas da União (TCU), órgão responsável pelo controle externo, como auxiliar do Congresso Nacional nessa missão de fiscalização financeira.

A Constituição, em seu artigo $70, \$ 1^{\circ}$, é clara ao estabelecer que "Prestará contas qualquer pessoa física ou jurídica, pública ou privada, que utilize, arrecade, guarde, gerencie ou administre dinheiros, bens e valores públicos ou pelos quais a União responda, ou que, em nome desta, assuma obrigações de natureza pecuniária”.

Desde já, se pode constatar, da leitura do artigo 70 da Constituição, que a interpretação do dispositivo leva à conclusão de que a fiscalização deve ser a mais abrangente e ampla possível, evitando-se restrições que só tendem a prejudicar a transparência das contas do setor público.

Mesmo assim, até pouco tempo atrás, a atuação dos órgãos de fiscalização financeira do setor público era bastante restritiva no que tange às empresas estatais, consoante se pode constatar das decisões do Supremo Tribunal Federal nos Mandados de Segurança 23.875-5/DF e 23.627-DF (julgados de 7 de março de 2002), em decisóes envolvendo a atuação do TCU no Banco do Brasil. Prevalecia o argu-

2 Sem recursos, CGU reduz suas ações de combate às fraudes. Folha de S.Paulo, 6 de outubro de 2014.

3 Governo investiga seis por suspeita de propina na Petrobras. Folha de S.Paulo, 13 de novembro de 2014, p. A4; Suspeita de corrupção - CGU abre 9 processos administrativos contra servidores da Petrobras. Revista Consultor Jurídico, 2 de dezembro de 2014.

4 Crise fará com que estatais fiquem mais transparentes, diz Jorge Hage, Folha de S.Paulo, 13 de dezembro de 2014. 
mento, em síntese, de que são entidades de direito privado, o que não permitiria considerar haver bens públicos a serem submetidos ao controle pelo TCU. Mais recentemente, após os escândalos envolvendo os Correios, outra empresa estatal, que deram início ao caso do "mensalão", houve alteração na posição de nossa $\mathrm{Su}$ prema Corte, expressamente manifestada no MS 25.181-6/DF (julgado de 10 de novembro de 2005), ao decidir que "Ao Tribunal de Contas da União incumbe atuar relativamente à gestão de sociedades de economia mista. Nova inteligência conferida ao inciso II do art. 71 da Constituição Federal, ficando superada a jurisprudência que veio a ser firmada com o julgamento dos Mandados de Segurança n. 23.627-2/DF e 23.875-5/DF".

Embora não pairem mais dúvidas sobre o poder fiscalizatório do Tribunal de Contas da União sobre as empresas estatais federais, o que já se pode constatar pelas muitas ações deste órgão, inclusive em relação à Petrobras, ${ }^{6}$ como se vê dos vários procedimentos abertos envolvendo a Petrobras, incluindo a compra da refinaria Abreu e Lima, a compra da refinaria de Pasadena (Estados Unidos) ${ }^{7}$ e tantos outros, ainda não se estabeleceram com segurança os exatos limites e poderes no exercício dessa fiscalização, gerando insegurança tanto para os órgãos responsáveis por ela quanto para as empresas a ela sujeitas, evidenciando ser esse um aspecto que merece melhor atenção por parte dos legisladores e estudiosos, a fim de sanar lacunas e omissões, e trazendo maior segurança jurídica ao sistema.

Os Tribunais de Contas, que no próximo dia 17 de janeiro comemoram seu dia, quando também completará 122 anos da instalação do Tribunal de Contas da União, criado em 1890 e contemplado na Constituição de 1891 (art. 89), cujas importantes atribuições já foram destacadas em coluna publicada ano passado terão este ano muito trabalho pela frente.

Da atuação do TCU dependerá boa parte das investigações e informações que permitirão a apuração dos fatos que já causaram irreparáveis prejuízos não só financeiros, mas também e principalmente à boa imagem da maior empresa do País,

5 GOMES, Emerson C. S. Responsabilidade financeira. Porto Alegre: Núria Fabris, 2012, p. 208-209.

6 Conforme se pode verificar de notícias publicadas na mídia: TCU sugere reter verbas de refinaria da Petrobras, em 5 de novembro de 2014, p. A7, TCU diz que alertou governo sobre Petrobras, em 12 de novembro de 2014, p. A9 e TCU identifica sobrepreço em gasoduto, em 5 de janeiro de 2015, p. A5 (Folha de S.Paulo); Técnicos alertaram para 'consolidação de danos' após veto de Lula, em 22 de novembro de 2014 (O Estado de S.Paulo), e Petrobras criou empresa de fachada para construir gasoduto bilionário, em 4 de janeiro de 2015 (O Globo).

7 TCU, AC 1.927/2014 - Plenário, Proc. TC 005.406/2013-7, j. 23.7.2014, rel. Min. José Jorge, 324 páginas. 
o que se reflete na imagem do Brasil no exterior. O TCU tem grande responsabilidade em mostrar a independência que a Constituição lhe assegura para prestar as informações e auxílio técnico que colaborem para extirpar essa mancha que causou prejuízos financeiros e morais ao País. Fiscalizar a Petrobras não é tarefa simples, dado seu gigantismo e complexidade, mas isso é só mais um desafio que o TCU terá de superar.

Mais do que isso, cabe-lhe, no exercício de suas atribuições constitucionais, que são bastante amplas, como se pode constatar do artigo 71 da Constituição, continuar realizando inspeções a auditorias (inciso IV), como as que já apuraram várias irregularidades em atos da Petrobras, aplicar as sançōes aos responsáveis (inciso VIII), e tantas outras. Ser mais rigoroso na aplicação das punições é medida que se impõe ante os desmandos que se têm verificado. Especial atenção deve ser dada ao seu regulamento próprio de licitaçôes, veiculado pelo Decreto 2.745/1998 (conforme previsto no artigo 67 da Lei 9.478/1997), que amplia em muito a discricionariedade do gestor nas contratações da empresa, abrindo a possibilidade de direcionamento de licitações e malversações de recursos públicos, tais como os que estão sendo apontados na empresa. ${ }^{8}$

A Presidente Dilma Rousseff, em seu discurso de posse, foi enfática em destacar que combaterá a corrupção: "Democratizar o poder significa combater energicamente a corrupção. A corrupção rouba o poder legítimo do povo. A corrupção ofende e humilha os trabalhadores, os empresários e os brasileiros honestos e de bem. A corrupção deve ser extirpada”, destacando que sempre apoiou o combate à corrupção, "pela ação incisiva e livre de amarras dos órgãos de controle interno, pela absoluta autonomia da Polícia Federal como instituição do Estado, e pela independência sempre respeitada diante do Ministério Público", desejando que os corruptos e corruptores sejam exemplarmente punidos, comprometendo-se ainda, com relação à Petrobras, "apurar com rigor tudo de errado que foi feito e fortalecê-la cada vez mais". Mas, como bem colocado no editorial de O Estado de São Paulo de 6 de janeiro de 2015, "não é com discursos e a tentativa maliciosa de colocar a tranca depois da porta arrombada que o problema da Petrobras será resolvido".?

Todos esperamos medidas concretas, como a manutenção de um orçamento adequado para a CGU, e o fortalecimento e respeito à independência do Tribunal

8 A constitucionalidade deste regulamento tem sido questionada em face do artigo $173, \$ 1^{\circ}$, III, da Constituição, tanto no âmbito do TCU quanto do STF (TCU - Decisão 663/2002; STF, decisões monocráticas nos MS 25.888, 25.986 e outros).

9 Salvando a cara dos poderosos. O Estado de S.Paulo, 6 de janeiro de 2015, p. A3. 
de Contas da União, para que possam, além de exercer as funções que lhes são próprias, colaborar com o Congresso Nacional, a Polícia Federal, o Ministério Público e o Poder Judiciário, a fim de que os fatos sejam esclarecidos, os responsáveis identificados e punidos, e os servidores possam voltar a se orgulhar da empresa em que trabalham, superando esse vexame ocorrido em 2014 e que deverá perdurar ainda por muito tempo. ${ }^{10}$

10 Até porque, em termos de vexame, o da seleção brasileira em 2014 já foi mais do que suficiente... 
